\title{
ORIGINAL
}

\section{Suicide attempt by an overdose of sitagliptin, an oral hypoglycemic agent: A case report and a review of the literature}

\author{
Shinya Furukawa ${ }^{1)}$, Teru Kumagi ${ }^{1)}$, Teruki Miyake ${ }^{1)}$, Teruhisa Ueda ${ }^{1)}$, Tetsuji Niiya ${ }^{1)}$, Keiichiro Nishino ${ }^{2)}$, \\ Shigeto Murakami ${ }^{2}$, Masato Murakami ${ }^{2}$, Bunzo Matsuura ${ }^{1)}$ and Morikazu Onji ${ }^{1)}$ \\ 1) Department of Gastroenterology and Metabology, Ehime University Graduate School of Medicine, Toon, Japan \\ 2) Department of Internal Medicine, Murakami Memorial Hospital, Saijo, Japan
}

\begin{abstract}
Dipeptidyl peptidase-4 (DPP-4) inhibitors are a newer class of oral hypoglycemic agents for the management of diabetes that elevate the plasma concentration of active glucagon-like peptide- 1 via inhibition of DPP-4. They effectively lower not only glycosylated hemoglobin levels, but also fasting and postprandial plasma glucose levels. Patients with diabetes occasionally consume an overdose of oral hypoglycemic agents in suicide attempts: the prevalence of depression is high in patients with diabetes, and depression is a strong risk factor for suicide. We encountered an 86-year-old woman with type 2 diabetes and depression, who was transferred to the emergency room $4 \mathrm{~h}$ after ingestion of 1,700 mg of the DPP-4 inhibitor sitagliptin (1,700 mg is 17 times greater than the approved maximum dose). Upon arrival, she was fully conscious, plasma glucose was $124 \mathrm{mg} / \mathrm{dL}$, and serum immunoreactive insulin level was $5.81 \mu \mathrm{U} / \mathrm{mL}$. Thereafter, the plasma concentration of sitagliptin rose to $3,793 \mathrm{nM}$, which is 4.5 times higher than the value found under regular treatment with the maximum dose. The patient did not suffer from hypoglycemia, suggesting that a single oral overdose of sitagliptin is unlikely to cause hypoglycemia. A literature review of oral anti-diabetic agents revealed that overdose of biguanides is occasionally fatal when immediate intensive care is not provided. In summary, sitagliptin is a good treatment option for diabetic elderly patients or patients with psychiatric disorders who are suicidal and do not require insulin.
\end{abstract}

Key words: Dipeptidyl peptidase-4 inhibitors, Hypoglycemia, Overdose, Sitagliptin

DIPEPTIDYL PEPTIDASE-4 (DPP-4) inhibitors have recently been approved worldwide for the management of diabetes. Although insulin is a wellknown anti-diabetic agent that is occasionally used for attempting suicide, the effect of an oral overdose of anti-diabetic agents, such as sitagliptin, a DPP-4 inhibitor, remains unclear. The incidence of hypoglycemia across a range of sitagliptin doses $(50,100$, and 200 $\mathrm{mg}$ ) in a 12-week double-blind randomized controlled study in Japanese patients with type 2 diabetes mellitus was as low as $1.3-4.4 \%$ [1]. We present a case report of sitagliptin overdose in a suicide attempt. We also review the literature on overdose with oral antidiabetic agents, and highlight the best use of oral anti-

Submitted Aug. 5, 2011; Accepted Jan. 13, 2012 as EJ11-0390 Released online in J-STAGE as advance publication Jan. 21, 2012

Correspondence to: Shinya Furukawa, M.D., Ph.D., Department of Gastroenterology and Metabology, Ehime University Graduate School of Medicine, Shitsukawa, Toon, Ehime 791-0295, Japan. E-mail: shinya.furukawa@gmail.com diabetic agents in elderly people and in patients with psychiatric disorders.

\section{Case Report}

An 86-year-old woman with a 10-year history of type 2 diabetes mellitus was admitted to our hospital after sitagliptin overdose (1,700 mg: 34 tablets, $50 \mathrm{mg}$ each) in a suicide attempt. She had been suffering from depression, and was prescribed sitagliptin $50 \mathrm{mg}$ /day for 10 months; her HbA1c levels were stable at about 7.9\% (National Glycohemoglobin Standardization Program). On admission, she was conscious and alert. Her blood pressure was 124/80 mm Hg and body temperature was $36.5^{\circ} \mathrm{C}$. Blood glucose and immunoreactive insulin levels were $124 \mathrm{mg} / \mathrm{dL}$ and $5.81 \mu \mathrm{U} / \mathrm{mL}$, respectively. Other laboratory data were as follows: hemoglobin level, 12.3 $\mathrm{g} / \mathrm{dL}$; platelet count, $22.2 \times 10^{4} / \mu \mathrm{L}$; aspartate transaminase level, $18 \mathrm{U} / \mathrm{L}$; alanine transaminase, $11 \mathrm{U} / \mathrm{L}$; creatinine level, 0.89 mg/dL; and HbA1c level, 8.2\%. 
The patient was treated with $500 \mathrm{~mL}$ of $4.3 \%$ glucose intravenously at a rate of $20 \mathrm{~mL} / \mathrm{min}$ for the first 10 minutes. She was maintained on $1 \mathrm{~L}$ of intravenous $4.3 \%$ glucose for 10 hours until the following morning. As a total, we used $52 \mathrm{~g}$ glucose to prevent hypoglycemia. She did not suffer from hypoglycemia, and the next morning, she was allowed to have breakfast. She then resumed oral administration of $50 \mathrm{mg}$ of sitagliptin at midday. After hospitalization, her blood glucose levels were monitored frequently (once every hour) for 10 hours, and they fluctuated between 130 and 200 $\mathrm{mg} / \mathrm{dL}$. Thereafter, preprandial and postprandial blood glucose levels were measured for 3 days, and hypoglycemia did not occur.

Serial plasma concentrations of sitagliptin were measured using protein precipitation and tandem mass spectrometry as reported elsewhere [2]. The levels of sitagliptin in the plasma the day before, $16 \mathrm{~h}$ after, and 7 days after the overdose were 197, 3,793, and 686 $\mathrm{nM}$, respectively. The patient has since been followed up in an outpatient clinic without any adverse events being noted.

\section{Literature Review}

We conducted a MEDLINE review of the relevant medical literature on overdose with oral anti-diabetic agents, excluding co-injection of insulin, published from January 1960 to November 2011. We identified all reported cases and reviews using the following search terms: overdose, suicide, intentional, hypoglycemia, sulfonylureas (SU), biguanides, and diabetes.

Relevant publications were evaluated, and the information has been summarized in Tables 1 and 2 . Although we found reports on SU, biguanides, and meglitinides, there were no reports on $\alpha$-glucosidase inhibitors and thiazolidinediones.

\section{Sulfonylureas}

There were 7 full articles describing SU overdose

Table 1 Clinical characteristics and outcome of previously reported sulfonylureas overdose

\begin{tabular}{|c|c|c|c|c|c|c|c|c|c|}
\hline First author [reference] & Number & $\begin{array}{c}\text { Age } \\
\text { (range) }\end{array}$ & $\begin{array}{c}\text { Intentional } \\
\text { overdose }\end{array}$ & $\begin{array}{c}\text { Psychiatric } \\
\text { disorders }\end{array}$ & $\begin{array}{l}\text { Suicide } \\
\text { attempt }\end{array}$ & $\begin{array}{c}\text { Münchausen } \\
\text { syndrome }\end{array}$ & Death & $\begin{array}{c}\text { Accidental } \\
\text { overdose }\end{array}$ & Death \\
\hline Dougherty PP. [3] & 13 & $\begin{array}{l}49 \pm 29 \\
(1-80)\end{array}$ & 2 & 0 & 2 & $\mathrm{~N} / \mathrm{A}$ & N/A & 3 & 0 \\
\hline Glatstein M. [4] & 10 & $\begin{array}{c}8.6 \pm 6.6 \\
(2-17)\end{array}$ & 4 & $\mathrm{~N} / \mathrm{A}$ & 4 & $\mathrm{~N} / \mathrm{A}$ & 0 & 6 & 0 \\
\hline McLaughlin SA. [5] & 9 & $\begin{array}{l}41 \pm 15 \\
(19-63)\end{array}$ & 5 & $\mathrm{~N} / \mathrm{A}$ & 4 & $\mathrm{~N} / \mathrm{A}$ & 0 & 3 & 0 \\
\hline Quadrani DA. [6] & 93 & $\begin{array}{c}3.5 \pm 2.0 \\
(1-16)\end{array}$ & N/A & $\mathrm{N} / \mathrm{A}$ & $\mathrm{N} / \mathrm{A}$ & N/A & 0 & N/A & N/A \\
\hline Dewitt CR. [7] & 76 & $\begin{array}{l}60 \pm 24 \\
(0-91)\end{array}$ & 6 & $\mathrm{~N} / \mathrm{A}$ & $\mathrm{N} / \mathrm{A}$ & 3 & $\mathrm{~N} / \mathrm{A}$ & 11 & N/A \\
\hline Klonoff DC. [8] & 69 & $35 \pm 14$ & 26 & 9 & N/A & N/A & $\mathrm{N} / \mathrm{A}$ & 43 & N/A \\
\hline Carr R. [9] & 8 & $\begin{array}{l}36 \pm 19 \\
(5-46)\end{array}$ & 2 & N/A & $\mathrm{N} / \mathrm{A}$ & $\mathrm{N} / \mathrm{A}$ & 0 & 1 & 0 \\
\hline
\end{tabular}

Table 2 Clinical characteristics and outcome of previously reported biguanides overdose

\begin{tabular}{lccccccccc}
\hline First author [reference] & Number & $\begin{array}{c}\text { Age } \\
\text { (range) }\end{array}$ & $\begin{array}{c}\text { Intentional } \\
\text { overdose }\end{array}$ & $\begin{array}{c}\text { Suicide } \\
\text { attempt }\end{array}$ & MALA & Death & $\begin{array}{c}\text { Accidental } \\
\text { ingestion }\end{array}$ & $\begin{array}{l}\text { MALA } \\
\text { Death }\end{array}$ \\
\hline Forrester MB. [10] & 1528 & $\begin{array}{c}50.5^{\star *} \\
(20-96)\end{array}$ & 439 & 420 & N/A & N/A & 1039 & N/A & N/A \\
Wills BK. [11] & 412 & N/A & 219 & N/A & 13 & N/A & 190 & 1 & N/A \\
von Mach MA. [12] & 109 & N/A & 62 & 62 & 6 & 3 & 47 & 8 & 1 \\
Peters N. [13] & 160 & $66.8 \pm 13.6$ & 5 & 5 & 3 & 0 & N/A & N/A N/A N \\
\hline
\end{tabular}

*includes suspicious suicide attempt **The age was available in 1316 patients.

MALA, metformin-associated lactic acidosis; N/A, not applicable 
and each included at least 8 patients (Table 1). Of these 7 articles, 2 were from pediatric centers and 5 from adult-care facilities. There were 10 patients from 3 reports in total who overdosed on SU in suicide attempts [3-5]. Their ages ranged from 13 to 44 years and 8 of them (80\%) were younger than 20 years. They were all treated appropriately with a combination of charcoal, octreotide, and dextrose. Quadrani et al. reported on 93 children (mean age, 3.5 (from 1 to 16) years) who were each given an overdose of SU by a parent suffering from Münchausen syndrome [6]. The remaining 3 reports did not give detailed information on the suicide attempts, but included patients who had self-destructive habits, psychiatric disorders (including Münchausen syndrome), or caregivers with Münchausen syndrome and were given an overdose of SU intentionally [7-9].

\section{Biguanides}

There were 4 relevant reports including more than 100 patients that described biguanides (metformin) overdose in suicide attempts (Table 2). The Texas Poison Center Control Network reported on 1,528 patients (58\% of them also used either non-biguanide oral hypoglycemic agents or insulin), and indentified that those whose overdoses were more than 5,000 $\mathrm{mg}$ and less than 2,500 $\mathrm{mg}$ of metformin differed in the rate of suspected attempted suicide $(81 \%$ vs. $6 \%)$, serious final medical outcome (19\% vs. $6 \%$ ), and referral to healthcare facilities (83\% vs. 3\%) [10]. Patients who were suspected of attempted suicide were also more likely to have co-ingestion compared with those who were not. A similar report from the Washington and Illinois Poison Center found that 13 of 219 suicidal patients who consumed an overdose intentionally presented with metformin-associated lactic acidosis (MALA), with 1 patient death [11]. Von Mach et al. reported on 109 patients (mean age, 58 years) with metformin overdose from a poison center in Germany, with 62 of them being suicidal. Six patients suffered from complications due to MALA, and 4 of them succumbed to the complications [12]. Peters et al. reported on 30 patients (including 5 suicidal ones) from an intensive care unit in France with MALA after metformin overdose, and all of them survived after appropriate care, with hemodialysis being the major component of treatment [13].

\section{Glinides}

In Japan, there was only 1 case report on glinides overdose in a suicide attempt. A 30-year-old non-diabetic woman with a history of psychiatric disorder requiring minor tranquilizers was transferred to a hospital an hour after an overdose of nateglinide that had been prescribed for her diabetic partner [14]. After careful monitoring of serum glucose and insulin levels, she was discharged without any adverse events.

\section{Discussion}

Although the use of oral anti-diabetic agents differs slightly among countries according to their guidelines and treatment algorithms [15], any oral anti-diabetic agent may lead to death when ingested excessively. A review of overdose with oral anti-diabetic agents showed that biguanides are likely to be the most frequently encountered agent that may lead to death when intensive care is not provided promptly, although SU are not reported on as often as biguanides. There were no reports of any patient deaths from SU overdose as a suicide attempt. However, the age range for SU overdose is much larger than that for biguanides. The reports on SU include children who were given overdoses by their caregivers who had Münchausen syndrome by proxy: this was not the original target population of the literature review but this type of overdose is noteworthy.

Sitagliptin is a very strong inhibitor of DPP-4, as shown in a study of healthy subjects where single oral dose (sitagliptin $50 \mathrm{mg}$ ) and multiple oral doses (sitagliptin $50 \mathrm{mg} /$ day $\times 10$ days ) resulted in $77.1 \%$ and 79.9\% inhibitory potency, respectively. Interestingly, its inhibitory potency remained above $93 \%$ at a much higher dose of $800 \mathrm{mg}$ [16]. These data suggest that the inhibitory potency of DPP-4 reaches a plateau despite elevated plasma sitagliptin levels. This partly explains there was no sudden decrease in blood glucose in the patient reported in our case study. It has also been reported that sustained exposure to glucagon-like peptide- 1 at a high concentration can correct hyperglycemia, but does not cause hypoglycemia due to a glucose-dependent decline in plasma insulin levels [17]. Strong inhibition of DPP-4 has the potential to cause a sustained elevation of plasma incretin hormone levels. However, due to the glucose-dependent nature of the activity of incretins, this could also contribute to preventing hypoglycemia after sitagliptin overdose.

Pharmacokinetic parameters $\left(T_{\max }\right.$ and $\left.C_{\max }\right)$ after a single oral dose of sitagliptin (400 mg and $800 \mathrm{mg}$ ) in 
healthy volunteers have been reported as follows: $1.5 \mathrm{~h}$ and $3640 \mathrm{nM}$, respectively, for $400 \mathrm{mg}$; and $1.0 \mathrm{~h}$ and 11,100 nM, respectively, for $800 \mathrm{mg}$ [16]. This study showed that the immediate absorption of sitagliptin is followed by the rapid rise in plasma sitagliptin levels. The maximum plasma level of sitagliptin was 3,790 $\mathrm{nM}$ in the woman in our case report: she had ingested $1,700 \mathrm{mg}$ of sitagliptin, which is equivalent to the $C_{\max }$ in a healthy volunteer ingesting sitagliptin $400 \mathrm{mg}$ for 10 consecutive days. In addition, Herman et al. reported that that single oral dose of $600 \mathrm{mg}$ sitagliptin resulted in a $C_{\max }$ of 7,000- 8,440 $\mathrm{nM}$ at $1.5-2 \mathrm{~h}$ after drug administration. However, the drug concentration declined to less than $1,000 \mathrm{nM}$ at $16 \mathrm{~h}$ after ingestion in the healthy subjects [18]. Taken together with the fact that the patient in our case report had plasma sitagliptin levels of 3,793 $\mathrm{nM}$ at $16 \mathrm{~h}$ after drug ingestion, it is easy to speculate that the patient was exposed to a significantly higher plasma sitagliptin level for a longer time than has been described in any reports available so far. Even so, the patient showed neither symptom- atic hypoglycemia nor any other adverse effects, suggesting that sitagliptin taken alone is a safe oral antihyperglycemic agent.

We could not completely exclude nocturnal hypoglycemia in our elderly patient who ingested 1,700 mg of sitagliptin. However, we did not observe evident hypoglycemia in this patient despite monitoring her blood glucose concentration carefully every few hours. This may be because: (1) blood glucose prior to the overdose of sitagliptin was poorly controlled; (2) it was a single oral overdose of sitagliptin; or (3) she did not take any other medications except sitagliptin. Nevertheless, we were able to find markedly elevated plasma sitagliptin levels even $16 \mathrm{~h}$ after drug ingestion. In conclusion, the present data suggest that a single overdose of sitagliptin is unlikely to cause fatal hypoglycemia and is thus one of the low-risk oral hypoglycemic agents. Sitagliptin should be considered for the treatment of diabetes in elderly people and in patients with psychiatric disorders who are suicidal.

\section{References}

1. Iwamoto Y, Tajima N, Kadowaki T, Nonaka K, Taniguchi T, Nishii M, Arjona Ferreira JC, Amatruda JM (2010) Dose-ranging efficacy of sitagliptin, a dipeptidyl peptidase-4 inhibitor, in Japanese patients with type 2 diabetes mellitus. Endocr J 57:383-394.

2. Zeng W, Xu Y, Constanzer M, Woolf EJ (2010) Determination of sitagliptin in human plasma using protein precipitation and tandem mass spectrometry. $J$ Chromatogr B 878: 1817-1823.

3. Dougherty PP, Klein-Schwartz W (2010) Octreotide's role in the management of sulfonylurea-induced hypoglycemia. J Med Toxicol 6(2):199-206.

4. Glatstein M, Garcia-Bournissen F, Scolnik D, Koren G (2010) Sulfonylurea intoxication at a tertiary care pediatric hospital. Can J Clin Pharmacol 17(1): e51-56.

5. McLaughlin SA, Crandall CS, McKinney PE (2000) Octreotide: an antidote for sulfonylurea-induced hypoglycemia. Ann Emerg Med 36(2):133-138.

6. Quadrani DA, Spiller HA, Widder P (1996) Five year retrospective evaluation of sulfonylurea ingestion in children. J Toxicol Clin Toxicol 34(3):267-270.

7. DeWitt CR, Heard K, Waksman JC (2007) Insulin and C-peptide levels in sulfonylurea-induced hypoglycemia: a systematic review. J Med Toxicol 3(3):107-118.

8. Klonoff DC, Barrett BJ, Nolte MS, Cohen RM, Wyderski R (1995) Hypoglycemia following inadvertent and factitious sulfonylurea overdosages. Diabetes
Care 18(4):563-567.

9. Carr R, Zed PJ (2002) Octreotide for sulfonylurea-induced hypoglycemia following overdose. Ann Pharmacother 36(11):1727-1732.

10. Forrester MB (2008) Adult metformin ingestions reported to Texas poison control centers, 2000-2006. Hum Exp Toxicol 27(7):575-583.

11. Wills BK, Bryant SM, Buckley P, Seo B (2010) Can acute overdose of metformin lead to lactic acidosis? Am J Emerg Med 28(8):857-861.

12. von Mach MA, Sauer O, Sacha Weilemann L (2004) Experiences of a poison center with metformin-associated lactic acidosis. Exp Clin Endocrinol Diabetes 112(4):187-190.

13. Peters N, Jay N, Barraud D, Cravoisy A, Nace L, Bollaert PE, Gibot S (2008) Metformin-associated lactic acidosis in an intensive care unit. Crit Care 12(6):R149.

14. Nakayama S, Hirose T, Watada H, Tanaka Y, Kawamori R (2005) Hypoglycemia following a nateglinide overdose in a suicide attempt. Diabetes Care 28(1):227228.

15. Nathan DM, Buse JB, Davidson MB, Ferrannini E, Holman RR, Sherwin R, Zinman B; American Diabetes Association; European Association for Study of Diabetes (2009) Medical management of hyperglycemia in type 2 diabetes: a consensus algorithm for the initiation and adjustment of therapy. A consensus statement of 
the American Diabetes Association and the European Association for the Study of Diabetes. Diabetes Care 32:193-203.

16. Bergman AJ, Stevens C, Zhou Y, Yi B, Laethem M, De Smet M, Snyder K, Hilliard D, Tanaka W, Zeng W, Tanen M, Wang AQ, Chen L, Winchell G, Davies MJ, Ramael S,Wagner JA, Herman GA (2006) Pharmacokinetic and pharmacodynamic properties of multiple oral doses of sitagliptin, a dipeptidyl peptidase-IV inhibitor: a double-blind, randomized, placebo-controlled study in healthy male volunteers. Clin Ther 28 (1):55-72.

17. Nauck MA, Kleine N, Orskov C, Holst JJ, Willms B, Creutzfeldt W (1993) Normalization of fasting hyper- glycaemia by exogenous glucagon-like peptide 1 (7-36 amide) in type 2 (non-insulin-dependent) diabetic patients. Diabetologia 36 (8):741-744.

18. Herman GA, Stevens C, Van Dyck K, Bergman A, Yi B, De Smet M, Snyder K, Hilliard D, Tanen M, Tanaka W, Wang AQ, Zeng W, Musson D, Winchell G, Davies MJ, Ramael S, Gottesdiener KM, Wagner JA (2005) Pharmacokinetics and pharmacodynamics of sitagliptin, an inhibitor of dipeptidyl peptidase IV, in healthy subjects: results from two randomized, double-blind, placebo-controlled studies with single oral doses. Clin Pharmacol Ther 78(6):675-688. 